\title{
Insilico Molecular Docking of Some Isolated Selected Compounds of Phoenix Sylvestris (L.) for Analgesic Activity
}

Ajoy Roy ${ }^{1}$, Md. Milonuzzaman ${ }^{2}$, Faisal bin Kader $^{1}$, Ameerul Islam ${ }^{1}$, Md Khurshed Alam ${ }^{1}$, Jahid Hasan $^{1}$, Md. Salman Faisal ${ }^{3}$, Shah Md. Asaduzzaman', Mahbubur Rahman ${ }^{4}$ and Mohuya Majumder ${ }^{5}$

${ }^{1}$ Department of Pharmacy, International Islamic University Chittagong, Bangladesh

${ }^{2}$ Department of Pharmacy, Jagannath University, Bangladesh

${ }^{3}$ Department of Pharmacy, Manarat International University, Bangladesh

${ }^{4}$ Department of Pharmacy, BGC Trust University Bangladesh, Bangladesh

${ }^{5}$ Department of Pharmacy, East West University, Bangladesh

*Corresponding author: Mohuya Majumder, Department of Pharmacy, East West University, Bangladesh

\begin{abstract}
ARTICLE INFO
Received: 梆 March 06, 2019

Published: March 20, 2019

Citation: Ajoy Roy, Md Milonuzzaman, Faisal bin Kader, Ameerul Islam, Mohuya Majumder, et al., Insilico Molecular Docking of Some Isolated Selected Compounds of Phoenix Sylvestris (L.) for Analgesic Activity. Biomed J Sci \& Tech Res 16(2)-2019. BJSTR. MS.ID.002820.
\end{abstract}

Keywords: Phoenix Silvestris (L.); Analgesic; Molecular docking; COX-1; COX-2

\begin{abstract}
Khejur palm (Phoenix Silvestris L. Roxb.) sometimes called the date palm is a very important and well-known source of sugar and is one of the most popular palms of Bangladesh. It is used to treat back pain, toothache, headache, arthritis, nervous debility and as a sedative. Our aim of the study to performed molecular docking studies to identify potential binding affinities of the phytocompounds from Phoenix Silvestris, namely 2, 3-Dihydro-3,5-dihydroxy-6-methyl-4H-pyran-4-one and 2,4-Di-tert-butyl phenol COX-1 and COX-2 for searching of the lead molecule against pain. A wide range of docking score found during molecular docking by Schrodinger. 2, 3-Dihydro-3,5-dihydroxy-6-methyl4H-pyran-4-one showed the docking score $-5.393 \mathrm{~kJ} / \mathrm{mol}$ against COX-1 \& 2,4-Di-tert-butyl phenol showed the docking score $-7.692 \mathrm{kj} /$ mol against COX-2. Between all the compounds 2, 3-Dihydro-3,5-dihydroxy-6-methyl-4H-pyran-4-one showed the best docking score towards COX-1 \& 2,4-Di-tert-butyl phenol showed the best docking score towards COX-2. So, 2, 3-Dihydro-3,5-dihydroxy-6-methyl-4H-pyran-4-one and 2,4-Di-tert-butyl phenol is the best compound respectively for COX-1and COX-2 enzyme inhibition, as it possessed the best value in Molecular Docking. Further, in vivo investigation needs to identify COX-1\& COX-2 enzyme inhibitory activity of isolated compounds from Phoenix Silvestris.
\end{abstract}

\section{Introduction}

Pain is an unpleasant sensory and emotional experience associated with actual or potential tissue damage or described in terms of such damage [1]. Irritations of pain receptor are given a feeling of pain, which can be found in the skin, joints and many internal organs. The cause of pain may also be damage to the nervous system, both the peripheral nerves, brain, and spinal cord. Pain can also occur without damage to tissues, although the patient refers to it (psychogenic pain). The process of pain is a complex phenomenon [2]. In the brain, pain stimulus is processed, and generated impulses are sent down the spinal cord following the appropriate nerves and instruct the body to respond, for instance withdrawing your hand from the fire. Peripheral nerves transmit pain stimulus to the spinal cord which then links to the brain [3]. An analgesic or painkiller is any member of the group of drugs used to achieve analgesia, relief from pain. They are distinct from anesthetics, which reversibly eliminate sensation. Analgesic substances interact with the transmitters and modulators of the pain system are helpful for many people with pain, but there is a great need for the development of better methods for the alleviation and control of both acute (immediate) and chronic (long-term, pathological) pain [4].

Analgesics including Nonsteroidal Anti-Inflammatory Drugs (NSAIDs) are commonly prescribed group of drugs in clinical practice for the management of pain and inflammation $[5,6]$. They 
work by interfering with Cyclooxygenase [COX] pathway, which involves the conversion of arachidonic acid by the enzyme COX to prostaglandins $[7,8]$. To suppress pain, NSAIDs are prescribed all over the world [9]. For severe or chronic malignant pain uploads analgesics are drugs of choice [3]. Despite wide clinical use of classical NSAIDs as analgesics, antipyretics, and anti-inflammatory agents their gastrointestinal toxicity is a major clinical limitation [5]. Different kinds of Studies have shown that opiates cause physical dependency, tolerance, and addiction while NSAIDs usually cause gastrointestinal disorders [10]. In this regard, herbal medicines from medicinal plants have been employed in Complementary and Alternative Medicine (CAM) for the treatment of pain as well as diseases related to these conditions [11].

The use herbal medicine is gaining support and recognition across the world because most of these products are believed to have bioactive compounds responsible for healing various diseases without any side effects and at a lower cost. Phoenix Silvestris Roxb. (Arecaceae), locally known as Khejur, is a palm tree cultivated for its syrupy juice and edible fruit in Bangladesh [12]. Palm is one of the important horticultural crops in many countries [13]. In Bangladesh, Khejur palm is produced as a homestead crop; however, it grows naturally or is cultivated in fallow lands, around homesteads, farmland boundary and even in the marginal lands along the roads and canals [14]. Fruits of the plant are used to treat back pain, stomachache, toothache, headache, arthritis, pain of buttocks, fever, piles, nervous debility, and as nervine tonic, restorative, sedative in ethnomedicine $[12,15]$. The sap of Khejur palm is a good source of vitamins of the B group and contains, in addition, a variable amount of ascorbic acid [16], freshly harvested sap consists of sucrose around $10 \%$, minimal invert sugar of $<0.5 \%$ and a small amount of protein, gums, and minerals.

Computational simulations of drug-target interactions using in silico molecular docking and molecular dynamics approaches are commonly used for the rational design and screening of drugs [17]. Molecular docking has become a major computational method for the prediction of ligand-receptor interactions [18]. A productive docking strategy must have the ability to adequately envision the local ligand represent the receptor limiting site (i.e. to find the trial ligand geometry inside a particular resistance confine) and the related physical-compound sub-molecular affiliations [19-22]. Furthermore, the aim of the study to find the mechanism of action of the isolated compounds from Phoenix Silvestris was explored the analgesic activity by molecular docking analysis.

\section{Materials and Methods}

\section{In silico Molecular Docking Protein Preparation}

Three-dimensional crystal structure of COX-1 (PDB id: 2OYE) and COX-2 (PDB id: 6COX) was downloaded in pdb format from the protein data bank [23]. After that, the structure was prepared and refined using the Protein Preparation Wizard of SchrödingerMaestro v10.1. Charges and bond orders were assigned, hydrogens were added to the heavy atoms, selenomethionines were converted to methionines and all waters were deleted. Using force field OPLS_2005, minimization was carried out setting maximum heavy atom RMSD (root-mean-square-deviation) to $0.30 \AA$.

\section{Ligand Preparation}

The structures of six major representative compounds i.e., Diethylnitrosamine (CID: 5921), 2, 3-Dihydro-3,5-dihydroxy-6methyl-4H-pyran-4-one (CID: 119838), 4-methylcatechol (CID: 9958), 2,4-Di-tert-butyl phenol (CID: 7311), and Diethyl Phthalate (CID: 6781) were obtained from PubChem database. The ligands were prepared with LigPrep tool embedded in Maestro 2015, neutralized at $\mathrm{pH} 7.0 \pm 2.0$ using Epik and minimized by force field OPLS_2005.

\section{Receptor Grid Generation}

Receptor grids were calculated for prepared proteins such that various ligand poses bind within the predicted active site during docking. In Glide, grids were generated keeping the default parameters of van der Waals scaling factor 1.00 and charge cutoff 0.25 subjected to OPLS 2005 force field. A cubic box of specific dimensions centered around the centroid of the active site residues (Reference ligand active site) was generated for the receptor. The bounding box was set to $14 \AA \times 14 \AA \times 14 \AA$ for docking experiments.

\section{Glide Standard Precision (SP) Ligand Docking}

SP flexible ligand docking was carried out in Glide of Schrödinger-Maestro v 10.1 [24,25]. within which penalties were applied to non-cis/trans amide bonds. Van der Waals scaling factor and partial charge cutoff were selected to be 0.80 and 0.15 , respectively for ligand atoms. Final scoring was performed on energy-minimized poses and displayed as Glide score. The bestdocked pose with lowest Glide score value was recorded for each ligand.

\section{Results and Discussion}

\section{In silico Molecular Docking Analysis}

Prediction of interaction energies between ligand and receptor has been a major challenge for molecular docking [26]. Virtual screening utilizes docking and scoring of each compound from a dataset. The technique used is based on predicting the binding modes and binding affinities of each compound in the dataset by means of docking to an X-ray crystallographic structure [27]. Grid-based docking study was used to analyze the binding modes of molecules with the amino acids present in the active pocket of the protein [28]. To identify the potential analgesic lead molecule, we have subjected the docking analysis of the active compounds of Phoenix Silvestris to the active site of COX-1 and COX-2. In order to study the interaction of the selected compounds Diethyl nitrosamine, 2, 3-Dihydro-3,5-dihydroxy-6-methyl-4H-pyran-4one, 4-methylcatechol, Diethyl Phthalate and 2,4-Di-tert-butyl phenol with COX-1 (PDB id: 2OYE) and COX-2 (PDB id: 6COX). We performed Glide docking analysis by Schrodinger suite v10.1, where among of these compounds 2, 3-Dihydro-3,5-dihydroxy-6methyl-4H-pyran-4-one shows highest docking score against COX1enzyme and 2,4-Di-tert-butyl phenol shows highest docking score against COX-2 enzyme.

Docking Score suggested that 2, 3-Dihydro-3,5-dihydroxy6-methyl-4H-pyran-4-one and 2,4-Di-tert-butyl phenol had the 
highest affinity toward the COX-1enzyme and COX-2 enzyme corresponding to the other compound. The results of docking analysis were described in Tables $1 \& 2$ and the docking figure showed in Figures $1 \& 2$. The colors indicate the residue (or species) type: Red-acidic (Asp, Glu), Green-hydrophobic (Ala, Val,Ile, Leu, Tyr, Phe, Trp, Met, Cys, Pro), Purple-basic (Hip, Lys, Arg), Blue-polar (Ser, Thr, Gln, Asn, His, Hie, Hid), Light gray-other (Gly, water), and Darker gray-metal atoms. Interactions with the protein are marked with lines between ligand atoms and protein residues: Solid pink- $\mathrm{H}$ bonds to the protein backbone, Dotted pink-H-bonds to protein side chains, Green-pi-pi stacking interactions, Orange-pi-cation interactions. Ligand atoms that are exposed to solvent are marked with gray spheres. The protein "pocket" is displayed with a line around the ligand, colored with the color of the nearest protein residue.
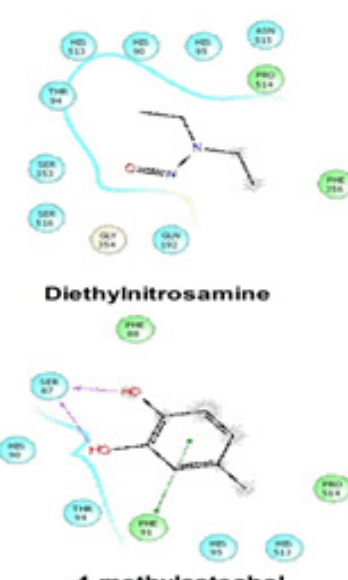

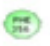

4-methylcatechol

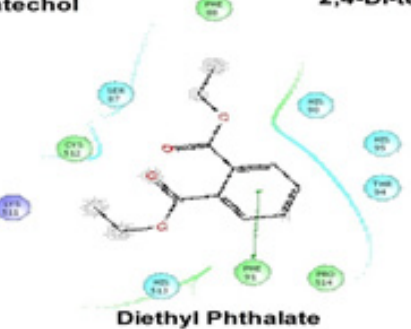

Figure 1: Schematic representation of the interactions between the best pose found for Diethyl nitrosamine, 2, 3-Dihydro-3,5dihydroxy-6-methyl-4H-pyran-4-one, 4-methylcatechol, 2,4-Di-tert-butyl phenol and Diethyl Phthalate with COX-1 (PDB id: 2OYE).
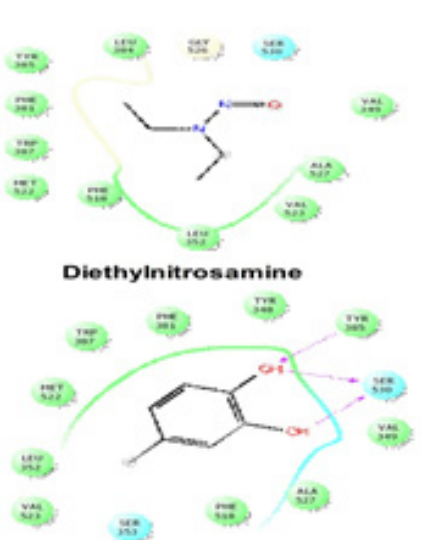

4-methylcatechol
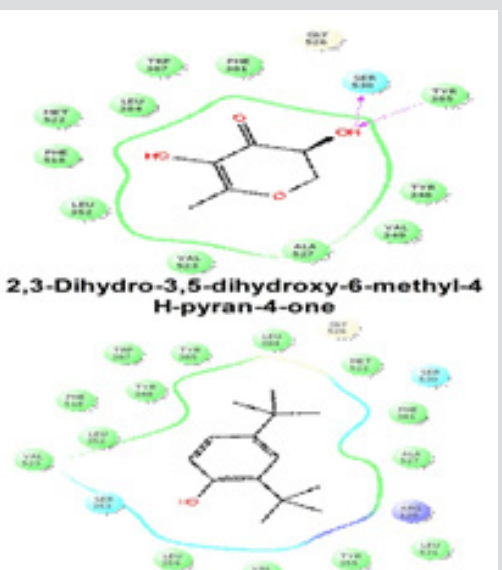

2,4-Di-tert-butylphenol

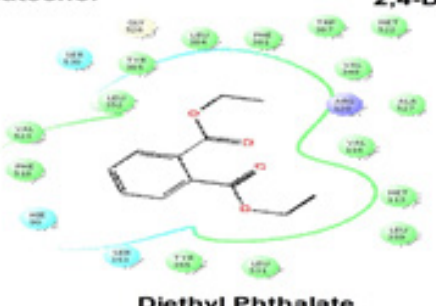

Figure 2: Schematic representation of the interactions between the best pose found for Diethyl nitrosamine, 2, 3-Dihydro-3,5dihydroxy-6-methyl-4H-pyran-4-one, 4-methylcatechol, 2,4-Di-tert-butyl phenol and Diethyl Phthalate with COX-2 (PDB id: 6COX). 
Table 1: Docking results of selected compounds with COX-1 (PDB id: 2OYE).

\begin{tabular}{|c|c|c|c|}
\hline Compound Name & Compound ID & Docking Score & Glide Energy \\
\hline Diethyl nitrosamine & 5921 & -3.571 & -15.749 \\
\hline $\begin{array}{c}\text { 2, 3-Dihydro-3,5-dihydroxy-6- } \\
\text { methyl-4H-pyran-4-one }\end{array}$ & 119838 & -5.393 & -23.563 \\
\hline 4-methylcatechol & 9958 & -5.07 & -17.154 \\
\hline 2,4-Di-tert-butylphenol & 7311 & -4.681 & -18.221 \\
\hline Diethyl Phthalate & 6781 & -3.993 & -24.243 \\
\hline
\end{tabular}

Table 2: Docking results of selected compounds with COX-2 (PDB id: 6COX).

\begin{tabular}{|c|c|c|c|}
\hline Compound Name & Compound ID & Docking Score & Glide Energy \\
\hline Diethyl nitrosamine & 5921 & -4.446 & -17.01 \\
\hline $\begin{array}{c}\text { 2, 3-Dihydro-3,5-dihydroxy-6- } \\
\text { methyl-4H-pyran-4-one }\end{array}$ & 119838 & -6.491 & -27.104 \\
\hline 4-methylcatechol & 9958 & -7.028 & -24.548 \\
\hline 2,4-Di-tert-butylphenol & 7311 & -7.692 & -25.981 \\
\hline Diethyl Phthalate & 6781 & -6.092 & -34.793 \\
\hline
\end{tabular}

The gap in the line shows the opening of the pocket. The colors indicate the residue (or species) type: Red-acidic (Asp, Glu), Green-hydrophobic (Ala, Val,Ile, Leu, Tyr, Phe, Trp, Met, Cys, Pro), Purple-basic (Hip, Lys, Arg), Blue-polar (Ser, Thr, Gln, Asn, His, Hie, Hid), Light gray-other (Gly, water), and Darker gray-metal atoms. Interactions with the protein are marked with lines between ligand atoms and protein residues: Solid pink-H-bonds to the protein backbone, Dotted pink-H-bonds to protein side chains, Green pi-pi stacking interactions, Orange-pi-cation interactions. Ligand atoms that are exposed to solvent are marked with gray spheres. The protein "pocket" is displayed with a line around the ligand, colored with the color of the nearest protein residue. The gap in the line shows the opening of the pocket.

\section{Conclusion}

The present study revealed that between the compounds 2, 3-Dihydro-3,5-dihydroxy-6-methyl-4H-pyran-4-one and 2,4-Ditert-butyl phenol showed the best docking score against COX-1 and COX-2 respectively. Further, in vivo investigation needs to identify COX-1 and COX-2 enzyme inhibitory activity of isolated compounds from $P$. sylvestris.

\section{Acknowledgment}

The authors thankful Mr. Arkajyoti Paul for providing the software and helping in manuscript writing.

\section{References}

1. Choudhury DK, Bezbaruah BK (2016) Prescribing pattern of analgesics in orthopedic in-patient department at tertiary care hospital in Guwahati, Assam, Northeast India. Indian J Pharmacol 48(4): 377.

2. Świeboda P, Filip R, Prystupa A, Drozd M (2013) Assessment of pain: Types, mechanism, and treatment. Pain 1: 2-7.

3. Koech SC, Ouko RO, Michael NM, Ireri MM, Ngugi MP, et al. (2017) Analgesic activity of dichloromethanolic root extract of Clutia abyssinica in Swiss albino mice. Nat Prod Chem Res 5(255): 2.

4. Basbaum AI, Fields HL (1978) Endogenous pain control mechanisms: Review and hypothesis. Ann Neurol Off J Am Neurol Assoc Child Neurol Soc 4(5): 451-462.
5. Taruna S, Dutta S, Dhasmana DC (2006) Prescribing pattern of NSAIDs in orthopaedic OPD of a tertiary care teaching Hospital in Uttaranchal. JK Sci 8: 3 .

6. Ravi PS, Partha P, Nagesh S (2002) Prescribing patterns in medical outpatients. Int J Clin Pract 56(7): 549-551.

7. Warner TD, Mitchell JA (2004) Cyclooxygenases: new forms, new inhibitors and lessons from the clinic. FASEB J 18(7): 790-804.

8. Vane JR (1971) Inhibition of prostaglandin synthesis as a mechanism of action for aspirin-like drugs. Nat New Biol 231(25): 232.

9. Boursinos LA, Karachalios T, Poultsides L, Malizos KN (2009) Do steroids, conventional non-steroidal anti-inflammatory drugs, and selective Cox2 inhibitors adversely affect fracture healing? J Musculo skelet Neuronal Interact 9(1): 44-52.

10. Fan S-H, Ali NA, Basri DF (2014) Evaluation of analgesic activity of the methanol extract from the galls of Quercus infectoria (Olivier) in rats. Evidence-Based Complement Altern Med 2014: 976764.

11. Singh A, Malhotra S, Subban R (2008) Anti-inflammatory and analgesic agents from Indian medicinal plants. Int J Integr Biol 3(1): 57-72.

12. Ghani A (1998) Medicinal plants of Bangladesh: Chemical constituents and uses. Asiatic Society of Bangladesh, pp. 467.

13. Chowdhury MSH, Halim MA, Muhammed N, Haque F, Koike M (2008) Traditional utilization of wild date palm (Phoenix sylvestris) in rural Bangladesh: An approach to sustainable biodiversity management. J For Res 19(3): 245-251.

14. Arntzen CJ (1994) Encyclopedia of agricultural science. RITTER, ELLEN M 2: 667.

15. Acharya E, Pokhrel B (2006) Ethno medicinal plants used by Bantar of Bhaudaha, Morang, Nepal. Our Nat 4(1): 96-103.

16. HALIM MDA, Chowdhury MSH, Muhammed N, Rahman M, Koike M (2008) Sap production from khejur palm (Phoenix sylvestris roxb) husbandry: A substantial means of seasonal livelihood in rural Bangladesh. For Trees Livelihoods 18(3): 305-318.

17. Jorgensen WL (2004) The many roles of computation in drug discovery. Science 303(5665): 1813-1818.

18. Kellenberger E, Rodrigo J, Muller P, Rognan D (2004) Comparative evaluation of eight docking tools for docking and virtual screening accuracy. Proteins Struct Funct Bioinforma 57(2): 225-242.

19. Arun Y, Saranraj K, Balachandran C, Perumal PT (2014) Novel spirooxindole-pyrrolidine compounds: Synthesis, anticancer and molecular docking studies. Eur J Med Chem 74: 50-64. 
20. Venkatachalam CM, Jiang X, Oldfield T, Waldman M (2003) Ligand fit: A novel method for the shape-directed rapid docking of ligands to protein active sites. J Mol Graph Model 21(4): 289-307.

21. Sharma DC (2012) Biochemical analysis and molecular characterization of wild India date palm Phoenix Sylvestris L Roxb.

22. Sangeeta Rani, Sudhir Chaudhary, Pradeep Singh, Garima Mishra (2011) Cressa cretica Linn: An important medicinal plant-A review on its traditional uses, phytochemical and pharmacological properties. Scholars Research Library 1(1): 91-100.

23. Berman HM, Westbrook J, Feng Z, Gilliland G, Bhat TN, et al. (2000) The protein data bank. Nucleic Acids Res 28(1): 235-242.

24. Friesner RA, Banks JL, Murphy RB, Halgren TA, Klicic JJ, et al. (2004) Glide: A new approach for rapid, accurate docking and scoring. 1. Method and assessment of docking accuracy. J Med Chem 47(7): 1739-1749.

\section{ISSN: 2574-1241}

DOI: 10.26717/BJSTR.2019.16.002820

Mohuya Majumder. Biomed J Sci \& Tech Res

This work is licensed under Creative

Commons Attribution 4.0 License

Submission Link: https://biomedres.us/submit-manuscript.php
25. Halgren TA, Murphy RB, Friesner RA, Beard HS, Frye LL, et al. (2004) Glide: A new approach for rapid, accurate docking and scoring. 2. Enrichment factors in database screening. J Med Chem 47(7): 17501759.

26. Babaheydari AK, Soureshjani EH, Salehi R (2013) Molecular docking analysis of compounds lavandula angustifolia mill with gabaa receptor lessen stress. $10(2)$.

27. Kumar A, Nisha CM, Silakari C, Sharma I, Anusha K, et al. (2016) Current and novel therapeutic molecules and targets in Alzheimer's disease. J Formos Med Assoc 115(1): 3-10.

28. Veeramachaneni GK, Raj KK, Chalasani LM, Annamraju SK, JS B, et al (2015) Shape based virtual screening and molecular docking towards designing novel pancreatic lipase inhibitors. Bioinformation 11(12): 535-542.

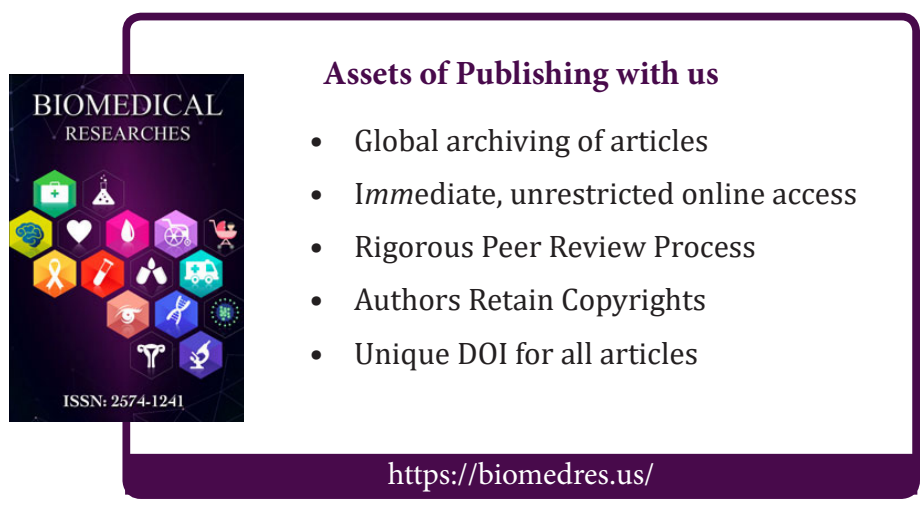

